\title{
On the synthesis and characterization of $\beta$-tricalcium phosphate scaffolds coated with collagen or poly (D, L-lactic acid) for alveolar bone augmentation
}

\author{
Isadora S. Deschamps ${ }^{1}$, Gabriel L. Magrin ${ }^{2}$, Ricardo S. Magini ${ }^{2}$, Márcio C. Fredel ${ }^{1}$, \\ Cesar A. M. Benfatti², Júlio C. M. Souza ${ }^{1,2}$
}

Correspondence: Dr. Júlio César Matias Souza

Email: julio.c.m.souza@ufsc.br

\begin{abstract}
'Department of Mechanical Engineering (EMC), Ceramic and Composite Materials Research Laboratories (CERMAT), Federal University of Santa Catarina (UFSC), Florianópolis, 88040-900, Santa Catarina, Brazil,

${ }^{2}$ Department of Dentistry (ODT), Center for

Education and Research on Dental Implants (CEPID), Postgraduation Program in Dentistry (PPGO), Federal University of Santa Catarina (UFSC), Florianópolis, 88040-900, Santa Catarina, Brazil
\end{abstract}

\section{ABSTRACT}

Objectives: After tooth loss, dimensional alterations on the alveolar bone ridge can occur that can negatively affect the placement of dental implants. The purpose of this study was to evaluate the synthesis, and mechanical properties of $\beta$-tricalcium phosphate $(\beta$-TCP) scaffolds coated with bioabsorbable polymers, namely, collagen and poly (D, L-lactic acid) (PDLLA). Materials and Methods: $\beta$-TCP powder was obtained by reactive milling and then characterized by $X$-ray diffraction and scanning electron microscopy/energy dispersive X-ray spectroscopy (SEM/EDS). $\beta$-TCP scaffolds were obtained by replica method, in which polyurethane foams are immersed in $\beta$-TCP suspension and thereafter submitted to a thermal treatment to remove the polyurethane and sinter the ceramic. Type-I collagen or PDLLA were used to coat the $\beta$-TCP scaffolds by dip-coating method. Scaffolds were separated in four groups depending on the coating material: noncoated (Group A), double immersion in collagen (Group B), double immersion in PDLLA (Group C), and ten immersions in PDLLA (Group D). Samples were characterized by compressive tests and SEM/EDS. Data were statistically analyzed through two-way ANOVA $(p=0.05)$. Results: Chemical and microscopic analyses revealed proper morphology and chemical composition of powder particles and scaffolds with or without polymeric coatings. Scaffolds coated with PDLLA showed higher compressive strength $(0.11 \pm 0.054 \mathrm{MPa})$ than those of collagen $(0.022 \pm 0.012 \mathrm{MPa})$ or noncoated groups $(0.024 \pm 0.012 \mathrm{MPa})$. Conclusions: The coating method of $\beta$-TCP with PDLLA revealed a potential strategy to increase the mechanical strength of porous ceramic materials while collagen can enhance cell migration.

Key words: Bioceramics, bone tissue engineering, dental implants, scaffolds

\begin{tabular}{|l|l|}
\hline \multicolumn{2}{|c|}{ Access this article online } \\
\hline Quick Response Code: \\
\hline
\end{tabular}

This is an open access article distributed under the terms of the Creative Commons Attribution-NonCommercial-ShareAlike 3.0 License, which allows others to remix, tweak, and build upon the work non-commercially, as long as the author is credited and the new creations are licensed under the identical terms.

For reprints contact: reprints@medknow.com

How to cite this article: Deschamps IS, Magrin GL, Magini RS, Fredel MC, Benfatti CA, M. Souza JC. On the synthesis and characterization of $\beta$-tricalcium phosphate scaffolds coated with collagen or poly (D, L-lactic acid) for alveolar bone augmentation. Eur J Dent 2017;11:496-502.

DOI: 10.4103/ejd.ejd_4_17 


\section{INTRODUCTION}

After tooth loss, dimensional alterations take place on alveolar bone ridge, resulting in complications for oral rehabilitation supported by dental implants. ${ }^{[1]}$ When the insertion of narrow diameter implants is not possible, bone augmentation procedures previous to implant placement is a viable option. ${ }^{[2]}$ Autogenous bone grafts are classically used due to their potential of bone formation, bio-absorption, and angiogenic characteristics. ${ }^{[3]}$ However, the need of a donor site for bone harvesting, increased surgical morbidity, and high rates of bone remodeling lead to the development of alternative materials for atrophic alveolar ridge treatment. ${ }^{[4]}$

Synthetic bio-absorbable scaffolds have emerged as an interesting possibility, decreasing the surgical morbidity, and therefore showing low rates of bone remodeling. ${ }^{[5,6]}$ The porous three-dimensional (3D) structure of synthetic scaffolds stimulates growth, migration, and differentiation of human cells for bone reparation. ${ }^{[7]}$ Those scaffolds should follow certain requirements, such as: possessing interconnected pores of proper size (100-800 $\mu \mathrm{m}$ in diameter) to allow the integration and vascularization of bone tissue; high wettability of the surface inducing cell adsorption and proliferation; controlled bio-integration and bio-absorption; adequate compressive strength ranging from 2 up to $10 \mathrm{MPa}$ (a compressive strength comparable to cancellous bone); and industrial viability to be synthesized on specific shapes and sizes. ${ }^{[8]}$

Calcium phosphate $(\mathrm{Ca} / \mathrm{P})$-based bone substitutes such as hydroxyapatite (HA), and $\beta$-tricalcium phosphate $(\beta-\mathrm{TCP})$ have been safely used in dentistry. ${ }^{[5,6,9,10]}$ Those ceramic scaffolds might have a proper pore size, which mainly depends on the manufacture technique. Several methods have been used to generate porosity in scaffolds, namely, replica foaming, direct gas foaming, freeze casting, model subtraction, and more recently, 3D printing. ${ }^{[9,11,12]}$ Those graft materials have been shown to resorb fully, being replaced by bone over a period from 6 up to 12 months. ${ }^{[13,14]}$ Even though ceramic scaffolds possess excellent biological behavior, their mechanical strength is low, especially because of the brittle porous structure. After sintering, a HA/ $\beta$-TCP scaffold acquires compressive strength mean values of about $0.05 \mathrm{MPa} \cdot{ }^{[15,16]}$

A large variety of polymer-based synthetic and natural biomaterials have been studied in the last years revealing good results..$^{[8,9,15,17]}$ The most common examples of polymers are cellulose, collagen, polyvinyl alcohol, poly(E-caprolactone), poly(lactic acid) (PLA), poly(glycolic acid) (PGA), poly(hydroxyl butyrate), poly(propylene fumarate), poly(lactic acid-co-glycolic acid) (PLGA), and poly(D, L-lactic acid) (PDLLA). They can be used as graft materials themselves or in association with metallic or ceramic structures. ${ }^{[8-10,17,18]}$ Considering the degradation of those polymers in nontoxic components, PLA, PGA, and their copolymers have been extensively used in the field of tissue engineering. ${ }^{[8]}$ In addition, those materials can be mixed with fragile structures to improve mechanical properties. ${ }^{[15-17]}$ In addition, antibiotics and growth factors can be embedded into polymeric structure to be released in bone tissue, providing a drug delivery capacity to the scaffold. ${ }^{[9,17]}$

Nowadays, the field of bone tissue engineering has investigated structures and materials that mimic human tissues properties. Bone is a complex tissue described as a natural composite of 70\% HA and 30\% collagen, possessing a natural functionally gradated porous structure. ${ }^{[1]]}$ Thus, synthetic scaffolds for bone formation should have a similarly porous composite structure with interpenetrating ceramic and polymer phases. ${ }^{[15]}$ Considering application, scaffolds are subjected to mechanical loads since their handling before bone placement up to osseointegration. ${ }^{[17]}$ Thus, the scaffold structure must withstand loading applied by the surgeon during placement into the defect site. ${ }^{[19]}$ In addition, load-bearing capacity is important to maintain bone volume and avoid tissue remodeling after placement of the scaffold. This fact might be highlighted when applying graft materials for periodontal and peri-implant regenerative therapies, once these materials can be under several mechanical stresses originated from occlusal forces. ${ }^{[18]}$

In fact, bone tissue engineering has experienced many challenges in the pursuit of a functionally scaffold for alveolar bone defects. The mechanical properties of the scaffolds during bone reparation are a clinical concern that can be overcome using different materials. The purpose of this study was to synthesize and evaluate the compressive strength of $\beta$-TCP scaffolds coated with bioabsorbable polymers, namely, PDLLA and collagen, for alveolar and peri-implant reparation. In addition, the influence of PDLLA layers on the compressive strength of the scaffolds was assessed in this study. It was hypothesized that bio-absorbable polymers such as PDLLA can increase the compressive strength of $\beta$-TCP scaffolds. 


\section{MATERIALS AND METHODS}

\section{Synthesis and characterization of $\beta$-tricalcium} phosphate powders

The $\beta$-TCP powder was synthesized by reactive milling using stoichiometric proportions as seen in Equation 1:

$2 \mathrm{NH}_{4} \mathrm{H}_{2} \mathrm{PO}_{4}+3 \mathrm{CaCO}_{3} \rightarrow$

$\mathrm{Ca}_{3}\left(\mathrm{PO}_{4}\right)_{2}+\mathrm{NH}_{3}+3 \mathrm{CO}_{2}+3 \mathrm{H}_{2} \mathrm{O}$

The dosage of the compounds was performed by gravimetric analysis (Bel, MARK210, Monza, Italy). Each synthesis route consisted of $30 \mathrm{~g} \mathrm{CaCO}_{3}, 22.986 \mathrm{~g}$ $\mathrm{NH}_{4} \mathrm{H}_{2} \mathrm{PO}_{4^{\prime}}$ and $500 \mathrm{ml}$ ethanol. Ethanol was selected as solvent due to its inertness to the compounds and easy removal after the synthesis. The mixture was milled in agate milling device, containing alumina milling balls of different sizes, following company's recommendations (U. S. Stoneware, Youngstown, Ohio, USA). After the process, the mixture was compacted into a stainless steel mold covered with filter paper up to full evaporation of ethanol. The dry powder was then roughly milled in an agate mortar (Jung, LF0612, Blumenau, SC, Brazil) and calcined.

X-ray diffractometry was carried out to identify crystalline phases using a Philips X'Pert equipment (PANalytical, Almelo, Netherlands). The radiation source was $\mathrm{Cu} \mathrm{Ka}$ radiation $(\lambda=0.15141 \mathrm{~nm})$, with $40 \mathrm{kV}$ and $30 \mathrm{~mA}$. The scan was performed continuously in 2-theta setting from $0^{\circ} \mathrm{C}$ to $100^{\circ} \mathrm{C}$ with step size of $0.02^{\circ} \mathrm{C}$, and a counting time of $2 \mathrm{~s}$ per step. The lattice parameters of the resulting powders were measured by energy-dispersive X-ray diffraction (XDR) (Philips X'pert, Almelo, Netherlands). Particle morphology and presence of agglomerations were analyzed by scanning electron microscopy (SEM) coupled to energy dispersive X-ray spectroscopy (SEM-EDS, JEOL USA JSM-6510 LV, Tokyo, Japan).

\section{Scaffold manufacturing}

The scaffolds were manufactured by replica method using 45 pores per inch (ppi) polyurethane foam pattern with $1 \mathrm{~cm}^{3}$ dimension and a $\beta$-TCP slurry. The replica method consists on dipping polymeric foam into ceramic slurry resulting in a porous structure coated with the ceramic material. Balanced rheological properties are required to ensure the coating since the fluid must flow when shear stress is applied, to remove the excess of fluid within the foam. After drying, the assembly was submitted to a thermal treatment to remove the polymeric foam and sinter the ceramic powder. The result of the process is a ceramic replica from the polymeric foam pattern.

In this study, the ceramic slurry was composed of $57 \%$ wt $\mathrm{H}_{2} \mathrm{O}, 43 \%$ wt $\beta$-TCP, and the following additives: 2\% wt carboxymethyl cellulose (1922 EMFAL, Jardim Piemonte, Brazil), 3\% wt Poly (vinyl alcohol) (P1763 Sigma Aldrich, St. Louis, USA), and 3\% wt citric acid (A1026.01. AH, Synth, Diadema, Brazil). Those components were mixed in the ball milling device (U. S. Stoneware, Youngstown, Ohio, USA), at $300 \mathrm{rpm}$ for $1 \mathrm{~h}$. The rheological behavior of all slurry compositions was evaluated directly after the milling process in a rotational coaxial cylinder (SV2P) using a viscometer (Viscotester VT550, Haake, Germany) at shear rate of $1 / \mathrm{s}$ from 0 up to $600 \mathrm{~Pa}$ and then from 600 down to $0 \mathrm{~Pa}$ at room temperature $\left(25^{\circ} \mathrm{C}\right)$.

After immersion of the polymeric foam in the $\beta$-TCP slurry, samples were air dried for $24 \mathrm{~h}$ prior to thermal treatment. The initial heating rate at $1^{\circ} \mathrm{C} / \mathrm{min}$ was performed to degrade slowly the polymeric foam maintaining the scaffold structure and to avoid the residues of incomplete firing. ${ }^{[20]}$

\section{$\beta$-tricalcium phosphate scaffolds coating with} bio-absorbable polymers

Ceramic scaffold samples were divided into four Groups (A, B, C, and D). Samples from Group B were coated with $0.5 \%$ Type I porcine collagen (Collagen Research Institute, Kiel, Germany) dissolved in distilled water. Samples from Group C and D were coated with 0.5\% PDLLA dissolved in chloroform (Proquímios, Bangu, Brazil). The polymer veneers were deposited on ceramic scaffolds by dip coating method into a solution of $2 \%$ of each polymer. After immersion, samples were dried at room temperature before each repetition of the dip coating process. Samples from the Groups B and C were immersed twice while samples from Group D were immersed ten times. Samples of Group A (control group) were not coated.

Total porosity of the scaffolds was measured using gravimetry, according to Equation 2:

Porosity $(\%)=\left(1-\rho_{\text {app }} / \rho_{t h}\right) \times 100$

Where $\rho_{\text {th }}$ is the theoretical density of the material, obtained by combining the molecular weight with unit cell volume, and $\rho_{\text {app }}$ is the apparent density, obtained by the weight divided by the geometrical measurement of the volume. 


\section{Compressive strength tests}

The compressive strength of the scaffolds was obtained by compressive tests at a rate of $1 \mathrm{~mm} / \mathrm{min}$, using a load cell with $100 \mathrm{~N}$ capacity (DL3000, EMIC, Brazil). The tests were performed at $23^{\circ} \mathrm{C}$ using a universal testing machine (Instron 8874, MA, USA). Specimens ( $n=5$ from each group) were positioned on the testing machine base and subjected to axial compressive loading up to fracture. The compressive force curves were recorded using the Trapezium (Shimadzu Corporation, Tokyo, Japan) software and the compressive strength values were calculated using the equation $F / \mathrm{w}^{2}$, whereas $F$ is the maximum load at fracture and $w$ the cross-section area of the specimen. ${ }^{[21]}$

\section{Scanning electron microscopy}

Scaffolds were dehydrated through a series of graded ethanol $(50,70,80,90$, and $100 \%)$ baths and then embedded in histological methacrylate resin. After, they were cross-sectioned in $100 \mu \mathrm{m}$ thick slices using a precise cutting machine (EXAKT 300/310 $\mathrm{CP}$, Norderstedt, Germany). Samples on each group were sputter-coated with Ag-Pd and then inspected using SEM (JEOL JSM-6390 LV, USA) coupled to an energy-dispersive $X$-ray spectroscope EDX (JEOL JSM-6390 LV, USA). Analyses were performed at secondary and back-scattered electron mode at $15 \mathrm{kV}$. The software Adobe Photoshop (Adobe Systems Software, Ireland) was used to analyze black and white images, with the black representing the pores and the white the bulk material. The porosity percentage was quantified by using ImageJ software (National Institutes of Health, USA).

\section{Statistical analyses}

Data were statistically analyzed through two-way ANOVA at a significance level of $95 \%(P=0.05)$ using the Statistical Package for Social Sciences 17.0 software for Windows (IBMSPSS, Chicago, IL, USA). In addition, Tukey's analysis was applied to compare groups.

\section{RESULTS}

\section{Chemical, rheological, and microscopic} characterization of powders

$\mathrm{XDR}$ and SEM images on $\beta$-TCP powders as well as rheology of ceramic slurry for scaffolds are shown in Figure 1. As seen in Figure 1a, XRD analyses of the powder confirmed the presence of $\beta$-TCP in accordance with the database. ${ }^{[22]}$ SEM analysis of the powder showed nanoscale particles disposed in agglomerates [Figure 1b]. EDS analysis revealed the

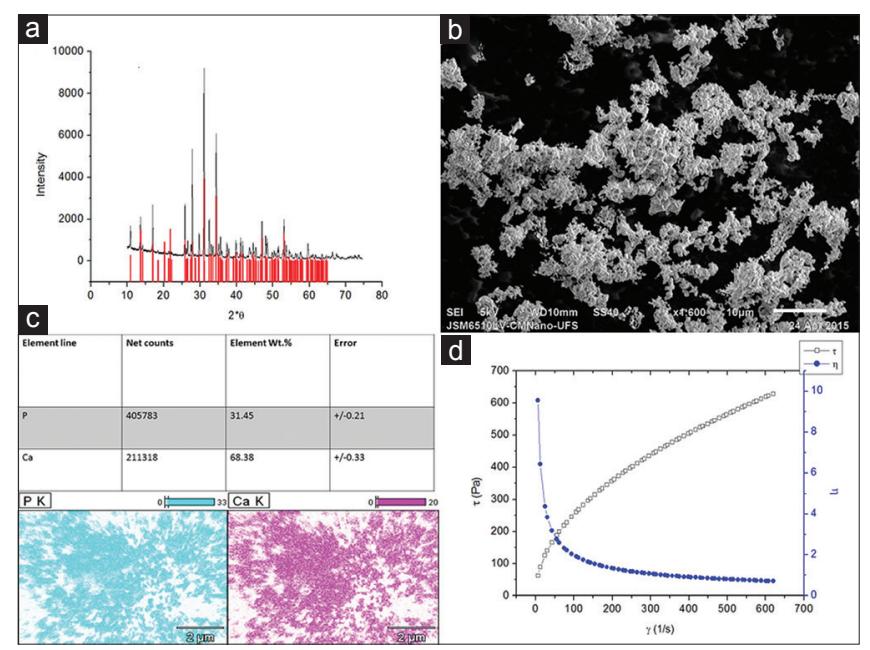

Figure 1: (a) X-ray diffraction patterns of $\beta$-tricalcium phosphate. $\mathrm{Cu}-\mathrm{K} \alpha$ radiation $(1.54056 \AA)$, scanning rate of $1.5^{\circ} \mathrm{min}^{-1}$, voltage of $40 \mathrm{kV}$ and current of $30 \mathrm{~mA}$. (b) SEM images micrograph of the powder particles obtained by secondary electron mode at $15 \mathrm{kV}$. (c) EDX map of the $\beta$-tricalcium phosphate powder. (d) Rheological behavior of the $\beta$-tricalcium phosphate slurry

presence of $\mathrm{Ca}$ and $\mathrm{P}$ at 1.68 ratio [Figure 1c]. The slurry showed a pseudoplastic behavior, decreasing its viscosity when shear stress was increased [Figure 1d]. Such behavior is desirable on the replica method since the slurry which block the pores can be released during compression of the sample while it can adhere to the struts when the stress is ceased.

\section{Compressive strength}

The mean values of compressive strength recorded on the $\beta$-TCP scaffolds coated with 10 layers of PDLLA [Figure 2] were significantly higher than those recorded on the other groups $(P<0.05)$. The highest mean values of compressive strength recorded on scaffolds coated with 10 layers of PDLLA were at $0.11 \pm 0.054 \mathrm{MPa}$. The scaffolds coated with double layer of PDLLA revealed compressive strength mean values of about $0.025 \pm 0.015 \mathrm{MPa}$ while scaffolds coated with double layer of collagen showed compressive strength mean values at $0.022 \pm 0.012 \mathrm{MPa}$. The noncoated $\beta$-TCP scaffolds showed compressive strength mean values at $0.024 \pm 0.012 \mathrm{MPa}$.

\section{Morphological analyses of the scaffolds}

SEM images of the scaffolds obtained by backscattered electrons are shown in Figures 3 and 4. The interconnected pore network of the polyurethane template was well replicated with very little blocking of the pores as seen in Figure 3. The sintered ceramic foams maintained the previous geometry and pore shape of the template foam. The spherical macro pore size of previous $45 \mathrm{ppi}(\sim 1000 \mu \mathrm{m})$ resulted in structures with mean pore size of about $738 \mu \mathrm{m}$ [Figure 3a]. 


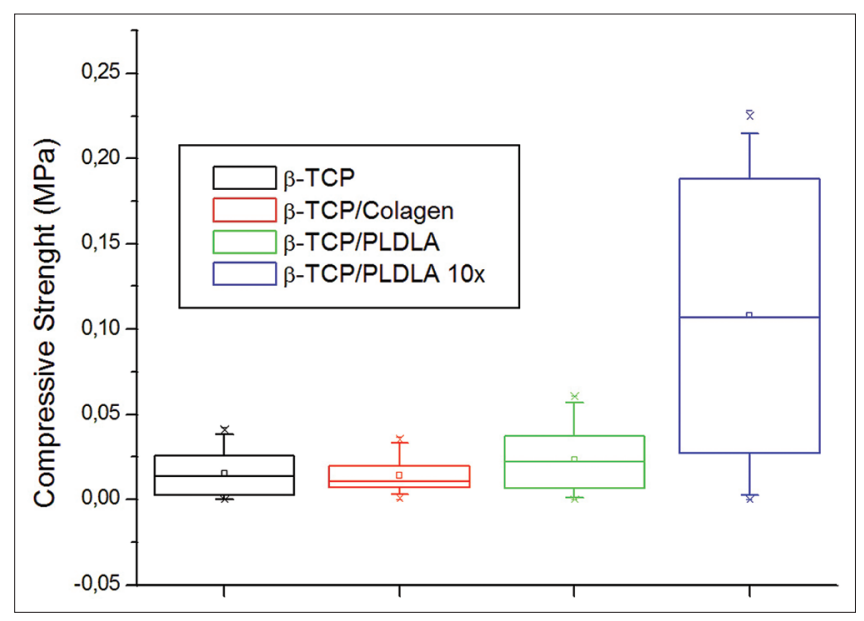

Figure 2: Mean values of compressive strength recorded on $\beta$-tricalcium phosphate scaffolds coated with poly (D, L-lactic acid) or collagen

However, the scaffolds coated with 10 layers of PDLLA revealed a pore size ranging from 200 up to $400 \mu \mathrm{m}$ [Figures 3d and 4]. All the porous structures formed a highly interconnected pore network [Figures 3 and 4]. The mean porosity $\beta$-TCP scaffolds free of coatings was around $86 \%$ while scaffolds coated with 10 layers of PDLLA had a mean porosity of about $44.6 \%$.

\section{DISCUSSION}

This study aimed to evaluate the synthesis route as well as the morphology and mechanical strength of $\beta$-TCP scaffolds, coated with two different polymers: collagen and PDLLA. The results of the present study reject the null hypothesis. Results showed that $\beta$-TCP scaffolds synthesized by the replica method provide proper size and morphology of the interconnected pore network. In addition, the coating of the $\beta$-TCP scaffolds with PDLLA (in the Group D) significantly increased the mechanical strength of the porous structures $(p<0.05)$.

In this study, the chemical composition used to synthesize the scaffolds was based on in vitro and in vivo results concerning biocompatibility and bone reparation. ${ }^{[5,7,8,10,11,13,18]}$ Several ceramic materials composed of $\mathrm{Ca} / \mathrm{P}$ have been used in bone reparation with predictable results. ${ }^{[5,6,19,23-27]}$ A patite-like ceramics such as $\beta$-TCP are commercially available due to its excellent osteoconductivity and biodegradability. The pursuit of a biodegradable synthetic bone substitute has led clinicians and the scientific community to look on the ceramic scaffolds as a feasible possibility. ${ }^{[5,6,19,23,25,27]}$

On the $\beta$-TCP scaffolds synthesized in this study, the porosity around $86 \%$ and pore size at about

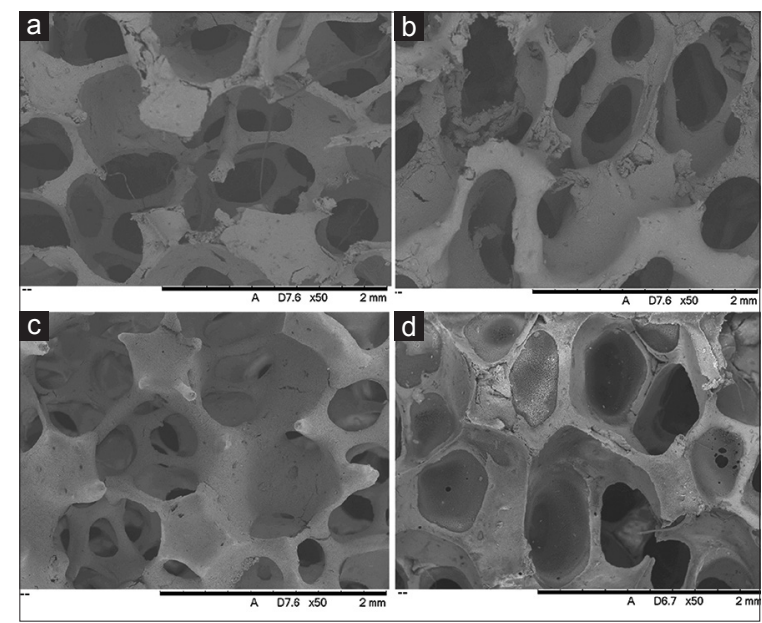

Figure 3: Scanning electron microscope images of the scaffolds. (a) Noncoated $\beta$-tricalcium phosphate scaffold. $\beta$-tricalcium phosphate scaffold coated with double layer of (b) collagen or (c) poly (D, L-lactic acid). (d) $\beta$-tricalcium phosphate scaffold coated with 10 layers of poly (D, L-lactic acid)

$738 \mu \mathrm{m}$ [Figure 3] are proper for angiogenesis, cellular migration, and bone growth, as found in the previous studies. ${ }^{[4-7,9,11,13,19,23,24]}$ Scaffolds coated with 10 layers of PDLLA showed porosity around $44.6 \%$ and pore size at about $200-400 \mu \mathrm{m}$ and therefore revealed an interconnected pore network [Figures $3 \mathrm{~d}$ and 4]. Depending on manufacture method, scaffolds can display a porosity ranging from 50 up to $80 \%$ and a pore size ranging from 150 up to $800 \mu \mathrm{m} \cdot$. $^{[9-11,13,19,23,24]}$ A network of interconnected micro- and macro-sized pores is critically important to induce bone growth into the structure. The ability of retain blood clot throughout the scaffold provides a pathway where osteogenic cells can migrate (osteoconduction). In fact, scaffolds might have a 3D architecture that mimics natural human trabecular bone. ${ }^{[5-13,15-19,23,24]}$ The trabecular bone left after the degradation of the structure allows functional loading and a dental implant placement. ${ }^{[23]}$

Although increased porosity and pore size facilitate bone ingrowth, porosity negatively affects the mechanical properties of scaffolds ${ }^{[11]}$ as found in the present study [Figure 2]. A proper mechanical behavior is important since the manipulation during the surgical procedure until loading after implantation in the bone defect. ${ }^{[10,11,17]}$ Thus, scaffolds for bone augmentation procedures must resist to compression from soft tissues as well as occlusal stress from mastication. ${ }^{[17,18,23]}$ In this study, PDLLA was used as coating material for the ceramic structure increasing the compressive strength of the scaffold [Figure 2]. Samples with PDLLA coating (especially Group D) revealed significantly higher compressive strength 

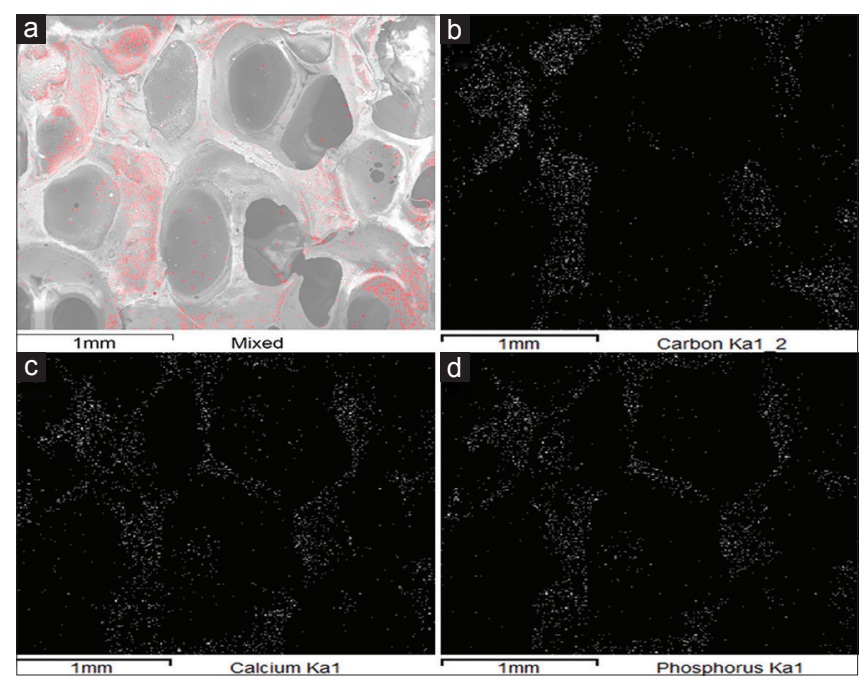

Figure 4: $\beta$-tricalcium phosphate scaffold coated with 10 layers of poly (D, L-lactic acid). (a) EDX mapping (red area) indicating (a) the poly (D, L-lactic acid), (b) carbon and (c) calcium and (d) phosphorus elements

when compared to scaffolds free of PDLLA $(p<0.05)$. The significant increase in compressive strength recorded for scaffolds coated with a thick layer of PDLLA (Group D) should be highlighted in our study. That indicates the influence of the polymeric thickness on the compressive strength of the scaffold.

Scaffolds composed of polymer and ceramic phases combine desirable properties of both materials to achieve a synergistic effect on their resultant properties. ${ }^{[5,7,9,13,15-18,23]}$ Indeed, $\beta$-TCP-based scaffolds coated with bioabsorbable polymers are a novel strategy to achieve good compressive strength, maintaining high biocompatibility, biodegradability, and osteoconductibility. The interpenetrating structure formed is probably responsible for the strengthening of the scaffold. The infiltration of the polymer in micropores and microcracks forms layered structures that reduce the propagation of cracks on loading. ${ }^{[25]}$ Another mechanism that can provide toughness to scaffolds is the crack bridging, once the polymer can stretch avoiding crack opening. ${ }^{[16,26]}$ Miao et al.(2008) stated that the compressive strength of HA/ $\beta$-TCP scaffold coated with PLGA was higher $(0.6 \mathrm{MPa})$ than that recorded on scaffolds free of polymer (0.05 MPa). ${ }^{[15]}$ Kang et al.(2011) also pointed to a significant improvement on mechanical performance of porous $\beta$-TCP scaffolds coated with PLGA. ${ }^{[16]}$

Recently, natural polymers such as collagen have been studied to coat ceramic scaffolds enhancing biological effects for bone augmentation. Alcaide et al. (2010) showed that coating HA/agarose scaffolds with Type-I collagen stimulated osteoblasts adhesion and therefore decreased the programmed cell death. ${ }^{[27]}$ In the present study, ceramic scaffolds coated with collagen (Group B) were evaluated concerning mechanical strength. Even though the collagen has not shown any influence on the compressive strength of the scaffolds, it could accelerate the bone reparation considering biointegration, the cell migration, and angiogenesis. ${ }^{[14]}$

\section{CONCLUSIONS}

Within the limitations of this study, it can be concluded that $\beta$-TCP scaffolds synthesized by the replica method showed proper morphology and size of interconnected pores to be used as bone substitute. In addition, coating $\beta$-TCP scaffolds with biodegradable polymers such as PDLLA is an advantageous method to increase mechanical strength of porous ceramic materials. Despite the fact that collagen coating did not reveal mechanical benefits on the scaffold structure, collagen can enhance cell migration, vascular organization, and consequent bone growth. Further studies should address the synergistic effect of combining synthetic and natural bioabsorbable polymers on cell migration and in vivo bone augmentation.

\section{Acknowledgments}

The authors acknowledge the financial support provided by Coordination for the Improvement of Higher Education Personnel (CAPES) and the Brazilian National Council for Scientific and Technological Development (CNPq). Also, the authors thank the Laboratory of Biomechanical Engineering of the University Hospital of UFSC (LEBm-HU/UFSC) for performing the compressive test.

\section{Financial support and sponsorship}

This study was financially supported by Coordination for the Improvement of Higher Education Personnel (CAPES) and the Brazilian National Council for Scientific and Technological Development (CNPq).

\section{Conflicts of interest}

There are no conflicts of interest.

\section{REFERENCES}

1. Araújo MG, Lindhe J. Dimensional ridge alterations following tooth extraction. An experimental study in the dog. J Clin Periodontol 2005;32:212-8.

2. Macedo JP, Pereira J, Vahey BR, Henriques B, Benfatti CA, Magini RS, et al. Morse taper dental implants and platform switching: The new paradigm in oral implantology. Eur J Dent 2016;10:148-54.

3. Tessier P, Kawamoto H, Matthews D, Posnick J, Raulo Y, Tulasne JF, et al. Autogenous bone grafts and bone substitutes - Tools and techniques: I. A 20,000-case experience in maxillofacial and craniofacial 
surgery. Plast Reconstr Surg 2005;116 5 Suppl: 6S-24S.

4. Acocella A, Bertolai R, Colafranceschi M, Sacco R. Clinical, histological and histomorphometric evaluation of the healing of mandibular ramus bone block grafts for alveolar ridge augmentation before implant placement. J Craniomaxillofac Surg 2010;38:222-30.

5. Samavedi S, Whittington AR, Goldstein AS. Calcium phosphate ceramics in bone tissue engineering: A review of properties and their influence on cell behavior. Acta Biomater 2013;9:8037-45.

6. LeGeros RZ. Calcium phosphate-based osteoinductive materials. Chem Rev 2008;108:4742-53.

7. Ma PX. Scaffolds for tissue fabrication. Mater Today 2004;7:30-40.

8. Okamoto M, John B. Synthetic biopolymer nanocomposites for tissue engineering scaffolds. Prog Polym Sci 2013;38:1487-503.

9. Liu Y, Lim J, Teoh SH. Review: Development of clinically relevant scaffolds for vascularised bone tissue engineering. Biotechnol Adv 2013;31:688-705.

10. Chen FM, Jin Y. Periodontal tissue engineering and regeneration: Current approaches and expanding opportunities. Tissue Eng Part B Rev 2010;16:219-55.

11. Karageorgiou V, Kaplan D. Porosity of 3D biomaterial scaffolds and osteogenesis. Biomaterials 2005;26:5474-91.

12. Do AV, Khorsand B, Geary SM, Salem AK. 3D printing of scaffolds for tissue regeneration applications. Adv Healthc Mater 2015;4:1742-62.

13. Horowitz RA, Mazor Z, Miller RJ, Krauser J, Prasad HS, Rohrer MD. Clinical evaluation alveolar ridge preservation with a beta-tricalcium phosphate socket graft. Compend Contin Educ Dent 2009;30:588-90, $592,594$.

14. Das S, Jhingran R, Bains VK, Madan R, Srivastava R, Rizvi I. Socket preservation by beta-tri-calcium phosphate with collagen compared to platelet-rich fibrin: A clinico-radiographic study. Eur J Dent 2016;10:264-76.

15. Miao X, Tan DM, Li J, Xiao Y, Crawford R. Mechanical and biological properties of hydroxyapatite/tricalcium phosphate scaffolds coated with poly (lactic-co-glycolic acid). Acta Biomater 2008;4:638-45.

16. Kang Y, Scully A, Young DA, Kim S, Tsao H, Sen M, et al. Enhanced mechanical performance and biological evaluation of a PLGA coated $\mathrm{B}$-TCP composite scaffold for load-bearing applications. Eur
Polym J 2011;47:1569-77.

17. Philippart A, Boccaccini AR, Fleck C, Schubert DW, Roether JA Toughening and functionalization of bioactive ceramic and glass bone scaffolds by biopolymer coatings and infiltration: A review of the last 5 years. Expert Rev Med Devices 2015;12:93-111.

18. Shimauchi H, Nemoto E, Ishihata H, Shimomura M. Possible functional scaffolds for periodontal regeneration. Jpn Assoc Dent Sci 2013;49:118-30.

19. Ikada Y. Challenges in tissue engineering. J R Soc Interface 2006;3:589-601.

20. Colombo P. Conventional and novel processing methods for cellular ceramics. Philos Trans A Math Phys Eng Sci 2006;364:109-24.

21. Rodrigues DS, Buciumeanu M, Martinelli AE, Nascimento RM, Henriques B, Silva FS, et al. Mechanical strength and wear of dental glass-ionomer and resin composites affected by porosity and chemical composition. J Bio Tribol Corros 2015;1:24.

22. Frondel C. Mineralogy of the calcium phosphates in insular phisphate rock. Am Mineral 1943;28:215-32.

23. Davies JE, Matta R, Mendes VC, Perri de Carvalho PS. Development, characterization and clinical use of a biodegradable composite scaffold for bone engineering in oro-maxillo-facial surgery. Organogenesis 2010;6:161-6.

24. Kido HW, Tim CR, Bossini PS, Parizotto NA, de Castro CA, Crovace MC, et al. Porous bioactive scaffolds: Characterization and biological performance in a model of tibial bone defect in rats. J Mater Sci Mater Med 2015;26:74.

25. Martínez-Vázquez FJ, Perera FH, Miranda P, Pajares A, Guiberteau F. Improving the compressive strength of bioceramic robocast scaffolds by polymer infiltration. Acta Biomater 2010;6:4361-8.

26. Nalla RK, Kinney JH, Ritchie RO. Mechanistic fracture criteria for the failure of human cortical bone. Nat Mater 2003;2:164-8.

27. Alcaide M, Serrano MC, Roman J, Cabañas MV, Peña J, Sánchez-Zapardiel E, et al. Suppression of anoikis by collagen coating of interconnected macroporous nanometric carbonated hydroxyapatite/agarose scaffolds. J Biomed Mater Res A 2010;95:793-800 